\title{
O tecnobrega no contexto do capitalismo cognitivo: uma alternativa de negócio aberto no campo performático e sensorial
}

\author{
Marcello M. Gabbay ${ }^{1}$ \\ Universidade Federal do Rio de Janeiro \\ marcellogabbay@uol.com.br
}

\begin{abstract}
Resumo: Este trabalho não pretende abordar questões estéticas a respeito do tecnobrega, mas, com base nos atuais conceitos de capitalismo cognitivo e capital imaterial, observar a evolução trilhada pelo gênero na cidade de Belém (PA), destacando as alternativas encontradas pelos atores desta cadeia produtiva cultural para estabelecerem-se no mercado local, diante de um processo de transição de paradigmas, onde antigos conceitos de tradição $e$ erudição, enrijecidos ao longo dos últimos quatro séculos, vêm cedendo espaço para novas formas de cultura e fala populares, amparadas no uso livre de tecnologias de comunicação e mídia.
\end{abstract}

Palavras-chave: Tecnobrega; Cultura popular; Capitalismo cognitivo.

Abstract: This article does not intend to approach aesthetic aspects about the tecnobrega style, but, based on the present conception about the "cognitive capitalism" and immaterial capital, analyze the evolution achieved by this music style at Belém city, highlighting the alternatives proposed by the participants of this cultural productive chain to establish themselves at the local market, in the face of a paradigm transition process, where old conceptions about tradition and erudition, settled through the last four centuries, are loosing the battle to new forms of popular culture and discourse, supported on the free use of new communication and media technologies.

Key-words: Tecnobrega; Popular culture; Cognitive capitalism.

\footnotetext{
${ }^{1}$ Mestrando em Comunicação e Cultura pela Escola de Comunicação da Universidade Federal do Rio de Janeiro. Membro do Laboratório de Estudos em Comunicação Comunitária da ECO/UFRJ - LECC.
} 
Extracto: Este artículo no se prepone acercar a aspectos estéticos sobre el estilo del "tecnobrega", sino, basado en el actual concepto sobre el "capitalismo cognoscitivo" y el capital inmaterial, analizar la evolución alcanzada por este estilo de la música en la ciudad de Belém, destacando los alternativas propuestos por los participantes de esta cadena productiva cultural para establecerse en el mercado local, frente a un proceso de transición del paradigma, donde los viejos conceptos sobre la tradición y la erudición, colocadas por los cuatro siglos pasados, están perdiendo la batalla para las nuevas formas de cultura y de discurso populares, apoyado en el uso libre de las nuevas tecnologías de la comunicación y de la media.

Palabras-claves: Tecnobrega; Cultura popular; Capitalismo cognoscitivo.

Abrégé: Cet article ne prévoit pas pour approcher des aspects esthétiques au sujet du modèle de tecnobrega, mais, basé sur la conception actuelle au sujet «du capitalisme cognitif» et du capital peu important, analyse l'évolution réalisée par ce modèle de musique à la ville de Belém, accentuant les solutions de rechange proposées par les participants de cette chaîne productive culturelle pour s'établir au marché local, face à un processus de transition de paradigme, où les vieilles conceptions au sujet de la tradition et de l'érudition, arrangées par les quatre derniers siècles, desserrent la bataille à de nouvelles formes de culture et de discours populaires, soutenu sur l'utilisation libre de nouvelles technologies de communication et de médias.

Mots clés: Tecnobrega; Culture populaire; Capitalisme cognitif.

\section{I - Capitalismo cognitivo, capital imaterial e consumo produtivo: uma breve revisão teórica.}

Para compreender o funcionamento dos novos sistemas de produçãocirculação-consumo-interação cultural, passando pelas novas modalidades de composição, direito autoral e de propriedade intelectual, distribuição material e imaterial e retro-alimentação da cadeia musical no tecnobrega, é preciso antes retomar as noções de capital imaterial e consumo produtivo como principais mudanças de paradigma no capitalismo contemporâneo, classificados por muitos autores como "capitalismo cognitivo". 
As antigas correntes evolucionistas, oriundas dos modelos fordista e taylorista, não dão conta de explicar esta mudança onde inovação não se resume meramente ao desenvolvimento do aparato tecnológico, e a raridade de matéria não defini mais a agregação de valor à produção. No capitalismo cognitivo a força de trabalho adquire sentido na especificidade do conhecimento e do sujeito que o produz, em sua capacidade subjetiva de criação. O trabalho imaterial, relacionado ao estreitamento entre produção e consumo, circulação e inovação, apresenta-se como um novo padrão de valor bem diferente do trabalho fabril assalariado.

No contexto do capitalismo cognitivo, o consumo não é mais destrutivo e sim produtivo (CORSANI, Antonella in COCCO, 2003: 28-29), de forma que a articulação das novas tecnologias, a "convergência multimídia", faz com que os usuários/consumidores transformem-se em usuários/produtores, rompendo a tradicional separação entre trabalho e meios de produção - o antigo controle sobre as tecnologias de produção e comunicação que centralizava e emissão de conteúdos em poucos grupos monopolistas - e entre mundo do trabalho e mundo da vida privada (COCCO, 2003: 8). Os novos parâmetros de produção no capitalismo cognitivo estabelecem-se justamente na interação entre produtores e usuários que formam, através do uso e apropriação das ferramentas informacionais (os softwares), redes coletivas de interação produtiva (denominadas netwares). Por isso, a inovação não depende apenas do aparato tecnológico, mas das interações, as redes de redes (COCCO, 2003: 10), onde as externalidades são o "lugar" da capacidade inovadora e as redes o "lugar" de sua valoração. Podemos assim entender que a circulação de conteúdos deixa de ser centralizada e, ao mesmo tempo, passa a ser o fator central na valoração do trabalho imaterial. Na cadeia produtiva do tecnobrega de Belém, a principal fonte de renda e trabalho são as apresentações ao vivo e festas de aparelhagem, o que propomos chamar de mercado da performance. Porém, o que movimenta este mercado, que já emprega mais 6.500 profissionais liberais (FGV et al.: 11), é justamente a circulação fluída de conteúdos, geralmente através de meios informais, como vendedores de rua e rádios-poste, ou seja, quanto mais músicas circulam, mais o mercado é movimentado no plano da performance e da experiência sensorial. 
Sob o ponto de vista do conceito de "império" de Hardt e Negri (2001: 49), o trabalho imaterial, na economia contemporânea, é o trabalho comunicativo de produção industrial ligado às redes de informação; o trabalho interativo de análise simbólica e resolução de problemas (interações, culturas), ou como afirma Corsani (in COCCO, 2003: 24), "a redução da incerteza e um domínio maior da complexidade" do mercado através das trocas de informações em rede; e o trabalho de produção e manipulação de afetos (sensações). Assim, as grandes corporações não produzem mais mercadorias, mas subjetividades, sensações de relação, "produzem produtores”. É sob esta ótica que o tecnobrega desponta como um circuito produtivo do capital imaterial. Cada vez mais, a sensação tem se tornado o foco central de valoração do produto cultural. O CD ou DVD enquanto formas materiais deixam de ser fundamentais para se tornarem suportes de conteúdo tão importantes quanto o MP3. O antropólogo Hermano Vianna detectou em Belém práticas de valoração das festas de aparelhagem a partir da experiência sensorial semelhantes a estratégias empreendidas por grupos dos circuitos da música independentes na Europa (os indies):

...algumas aparelhagens, ao lado do computador principal, usado pelo DJ para suas mixagens, agora também apresentam um outro computador que fica gravando toda a festa, e no final já consegue prensar uma quantidade razoável de CD's para venda imediata. Os DJ's são espertos: usam e abusam do microfone para, por cima das músicas, cumprimentarem os fã-clubes e outros dançarinos ou convidados ilustres (como músicos, produtores) presentes na festa. Essas pessoas acabam comprando o $\mathrm{CD}$, pois além de conter a seleção musical que acabam de dançar, ainda trazem a prova de que são respeitadas pelo DJ. É como comprar o jornal pois sua foto está publicada na coluna social. Beto Metralha [DJ e produtor local] me contou que usa esses CD's como divulgação do seu trabalho, mostrando ao mesmo tempo como as músicas que produziu têm feito sucesso e também como sua presença na festa é valorizada pelos principais DJ's do Pará (VIANNA, 2007: 3).

Desta forma, no capitalismo cognitivo, o capital imaterial "só tem valor se for "trocado", ou seja, não pode ser valorado a priori, mas a partir do momento em que passa a circular nas redes de relacionamento. O processo de criação/socialização de conteúdos (inclusive produtos culturais) não pode ser mais materializado em formas físicas, como um disco, um CD ou DVD, tão pouco podem ser convertidos em títulos de propriedade, de forma que a reserva de direitos de propriedade intelectual 
passa a representar uma espécie de "freagem" no processo de valoração criativa do conhecimento.

\section{II - Propriedade intelectual $X$ livre circulação de conteúdos: paradigmas dos mercados de produção e performance musicais.}

A especificidade do conhecimento e a revolução tecnológica do capitalismo e das novas tecnologias de comunicação implicam na redefinição do direito de propriedade intelectual. Os conhecimentos não são raros e não precisam ser propriedade individual para que sejam trocados ou socializados. Mas as grandes corporações procuram novas formas de "submissão formal" do conhecimento em novas políticas de propriedade intelectual, formando verdadeiros cartéis de enclausuramento, os enclousers (MOULIER-BOUTANG, 2001: 25-27). O conhecimento, ao contrário dos bens materiais, não é passível de apropriação individual, nem "divisível” porque agrega valor justamente nas trocas, conteúdos imateriais não são "bens rivais", mas sim bens "não-cambiáveis" e não-destrutíveis, ou seja, aquele que transmite não se despoja ou se aliena do bem, mas agrega valor. Assim, "a análise das relações de trabalho em termos de contrato jurídico não capta o essencial” que é a memória, a inovação criativa, a cooperação intangível (LAZZARATO, Maurizio in COCCO, 2003: 81).

É neste contexto que vêm surgindo várias propostas de reestruturação dos sistemas de direitos autorais e propriedade intelectual. Joost Smiers (2007: 1) propõe substituir-se o antigo sistema de copyright - que favorece mais às grandes indústrias culturais que propriamente aos artistas e territórios de cultura - por um sistema de direitos de propriedade restrito e limitado a um tempo menor, podendo uma obra muito popular cair em domínio público em poucos meses, por exemplo, variando de acordo com a situação de cada obra, artista, país, ou contexto político, econômico e sociocultural. A idéia é que o copyright seja uma forma de remunerar o artista num breve período entre uma criação e outra. Além disso, o "novo" direito daria ao autor propriedade sobre a obra e não sobre suas características (obras parecidas, casos de plágio). Afinal, a adaptação criativa é uma prática motriz em todas as culturas do mundo, e característica marcante em estilos que trabalham sobre plataformas informatizadas, como tecnobrega, o funk, as diversas variações da música eletrônica, o soul, e muitas outras. As práticas de "sampleagem", loops, e demais formas de 
bricolagem são recursos considerados como parte do processo criativo do compositor. Uma forma de regulação de direitos autorais mais aberta beneficiaria a dinâmica criativa da cultura contemporânea. O que ocorre, segundo Smiers (2007: 2), é que o sistema de copyright contradiz os direitos mencionados na Declaração Universal dos Direitos Humanos, onde é garantido a todos o acesso aos meios de comunicação e, aos artistas, a possibilidade de ganhar a vida com seu trabalho, vale lembrar também que em sua $3^{\text {a }}$ Conferência Geral, em 2001, a Unesco declarou a diversidade cultural como "patrimônio comum da humanidade", considerando-a "tão vital para a humanidade, quanto a diversidade biológica é para os organismos vivos" (MATTELART, 2006: 141-144). Por outro lado, Smiers põe em questão a figura do autor, que, para ele, exerce um trabalho de releitura criativa a partir de suas influências, um processo muito similar ao conceito de culturas híbridas de Canclini, que contesta identidades e processos culturais "autênticos" e "puros" diante de uma dinâmica sociocultural pautada na interação constante de referências culturais diversas (2006: XXIII). Canclini define hibridação como:

Processos socioculturais nos quais estruturas ou práticas discretas, que existiam de forma separada, se combinam para gerar novas estruturas, objetos e práticas... A hibridação ocorre em condições históricas e sociais específicas, em meio a sistemas de produção e consumo que às vezes operam como coações, segundo se estima na vida de muitos migrantes (CANCLINI, 2006: XIX).

Assim, os processos de autentificação e personalização da obra são parte do projeto capitalista que visa atribuir fama e valor econômico à arte e à figura do artista, onde este passa a ser um produto em si. De fato, o sistema de copyright "privatiza muito agressivamente terrenos completos de criatividade e desenvolvimento de conhecimentos. Isto supõe uma desvantagem para os futuros processos de criação e representação dos artistas" (SMIERS, 2007: 9). Para Smiers, o conceito de direito moral do autor sobre a obra é "demasiado romântico" (2007: 1011), porque pressupõe a originalidade da obra, excluindo o fato de que as inspirações criativas vêm de uma bagagem de vivências e experiências acumuladas a partir do contexto social e cultural do autor. Moulier-Boutang (2001: 39) demonstra que o direito moral funciona como manobra de articulação financeira para managers e produtores culturais, que administram os direitos como títulos financeiros e valiosas fontes de lucro. No capitalismo cognitivo, o autor/artista tem na obra o direito a 
renda em troca de uma atividade humana (a performance, por exemplo) e não mais uma espécie de fonte de renda perene, uma vez que o que se origina da obra não é mais um papel de direito negociável e rentável, mas um bem coletivo de conhecimento. Segundo Smiers, numa sociedade onde não existe propriedade individual em forma de copyright, não há pirataria; "se todo mundo pode copiar, é o fim da exclusividade dos piratas" (2007: 12).

Nos movimentos pelo copyleft (direitos autorais abertos), os mais atingidos não são os artistas, mas as grandes corporações culturais, que vêm travando uma batalha publicitária contra as possibilidades de produção aberta, difundindo o conceito mercadológico de propriedade intelectual, uma vez que, "durante anos, detiveram monopólios e direitos de exclusividade em todo o processo de produção e agora terão que encontrar outras formas de lucrar". "A arte monopolizada é a arte do domínio, que empacota e vende seguindo a cartilha do lucro. Arte livre é a arte de todos, aberta para a crítica, aberta para a intervenção e à apreciação universal”, por isso, o copyright, de muitas formas, restringe também a capacidade de difusão da obra e do trabalho do artista. "Quanto mais conhecido o trabalho de um artista, mais oportunidade ele terá de ser convidado para palestras, para fazer shows, participar de publicações, etc" (BONJOUR et. al, 2007: 11); esta é a filosofia das bandas e produtores do tecnobrega, que vêem na circulação livre de suas músicas uma forma de divulgação e multiplicação das apresentações ao vivo, estas sim a principal fonte de renda no gênero. A atribuição de novas formas de renda para a criação artística (através da performance, shows e contato real com o público, experiências valorizadas pelo aspecto sensorial), possibilita, através da maior circulação de conteúdos, além de um espectro bem mais amplo de formas de propagação, novas formas de apropriação criativa, releituras e hibridações culturais.

Neste contexto, diversas alternativas vêm sendo propostas como forma de atualizar e reestruturar as antigas políticas de controle e propriedade intelectual, como o Creative Commons ${ }^{2}$. Mas Ivana Bentes lembra que as mudanças nos sistemas

${ }^{2}$ O Creative Commons é um projeto desenvolvido na Universidade de Stanford, nos Estados Unidos, que visa possibilitar maior flexibilidade de usos criativos sobre obras autorais, protegendo o direito a autoria por meio de licenças jurídicas abertas, adaptadas à legislação dos países onde é praticada. No Brasil, as licenças Creative Commons são geridas pelo Centro 
sociais, econômicos e políticos em direção a organizações em redes distributivas carecem de uma estrutura mínima de tecnologias de informação e comunicação (as NTIC's), sistemas alternativos de informação e comunicação, softwares livres e um requisito cultural que é a "distribuição da inteligência de massa". Embora no Brasil, apenas $10 \%$ da população possua computador em casa. "Comunicação e cultura tornaram-se estratégicos para a sociedade civil”; assim, Ivana propõe um modelo de "cidades de cooperação" para fomentar uma filosofia colaborativa por compartilhamento de bens simbólicos e culturais (BENTES, 2007: 5-6).

\section{III - A questão do gosto brega e o surgimento comercial do tecnobrega.}

A história da música popular brasileira guarda lacunas escondidas pelo estigma do gosto e de suas apropriações como forma de distinção social. Diversos pesquisadores da etnomusicologia, antropologia e comunicação assumem e determinam o bom desempenho comercial - despontado por diversos motivos, muitas vezes relacionados às mudanças culturais e tecnológicas ou apropriações de produções populares por parte da indústria massiva - como pivô da passagem de determinados produtos musicais da arena brega ao consumo de classes superiores na escala sociocultural (GUERREIRO DO AMARAL, 2006a; ARAÚJO, 1999; FREIRE FILHO, 2003). Na década de 1960, a comercialização do brega "alavancou a indústria fonográfica nacional”, especialmente nas cidades de Recife, Goiânia e Belém (GUERREIRO DO AMARAL, 2006a: 3), o que não freou de forma alguma a distinção binarista entre povo e elites, respectivamente, popularesco e erudito, ou ainda, mau gostos e bom gosto, todas formas de distinção sociocultural a partir do consumo e do gosto.

No Pará, o brega ocupou um espaço na acirrada disputa pela produção musical regional durante as últimas três décadas. A forte presença da cultura européia em Belém e em Manaus, herança da belle époque da borracha no século XIX, é um dos fatores mais significativos para a construção e determinação dos padrões de bom gosto e alta cultura. $\mathrm{O}$ fato se deve muito às tradições culturais burguesas e a insistente manutenção de uma autenticidade original forjada pelas

de Tecnologia e Sociedade da Escola de Direito da Fundação Getúlio Vargas. Mais informações no site www.creativecommons.org.br. 
classes altas desde o período colonial, que instituíram a cultura européia como referência de comportamento, arquitetura, cultura e conhecimento. No final do século XIX - a partir da inauguração do Theatro da Paz em 1878 - as elites da borracha financiaram a apresentação de diversas óperas e concertos de autores europeus em Belém e em Manaus (SALLES, 1994: 88-126). Além de enviarem seus filhos para universidades européias, afim de que trouxessem de lá influências políticas e referenciais culturais para a construção de uma elite emergente na nova sociedade brasileira. Em Belém, a segregação cultural entre as heranças européias e as práticas culturais ritualísticas "primitivas" oriundas dos povos nativos e hibridações (os chamados caboclos) corroborava para a concepção de raças inferiores e incapazes intelectualmente. Desde então, os núcleos de influência e referência cultural e bases de poder estavam instalados no Rio de Janeiro, São Paulo, Minas Gerais e Bahia. As práticas culturais realizadas nestes territórios - fortemente imbricadas nas importações de costumes europeus - eram tidas como "modernas" e "atuais", de forma que as práticas realizadas nas demais regiões, com inferiores índices de desenvolvimento econômico, eram tidas como "folclóricas", "antigas" e "primitivas"; em reforço a esta idéia, havia ainda o real isolamento da região Amazônica que impedia o intercâmbio cultural com as regiões economicamente mais desenvolvidas, de forma que "estar longe do espaço europeizado significava estar situado num tempo passado, primitivo" (LOUREIRO, 2001: 41).

A partir da primeira metade do século XX, as elites paraenses pós-borracha viram-se inclinadas a assumirem a identidade cabocla, numa época em que o rústico e o "original" ganhavam valor de mercado no mundo globalizado. A procura por autenticidade no consumo espelha a grande polifonia de marcas, formas e idéias produzidas em série; recorrer à identidade amazônica e suas origens étnicas seria obter um diferencial no comércio imagístico. Só assim os rituais, batuques, danças, símbolos e dialetos caboclos puderam ser "elevados" a alta cultura, mas para tanto, tiveram de abrir mão de uma gama de significações sociais, políticas e culturais para assumirem uma qualidade essencialmente estética para o mercado simbólico da indústria cultural e do turismo.

Rodrigues (2005: 64-65) estabelece a segunda metade nos anos 1970 como marco da popularização dos dispositivos eletroacústicos para além dos ambientes 
universitários e científicos, abrindo espaço para uma maior "variedade estilística". Neste mesmo período, na Europa, os artistas passaram a tomar frente contra as velhas convenções binaristas erudito/popular, arte série/arte ligeira e arte/vida. Já nos anos 1980, o autor observa a ascensão dos DJ's como produtores musicais (que vinham das emissoras de rádio e, posteriormente, das pistas de dança; mais adiante passariam ao status de compositores), o que "oxigenou de modo notável os processos de invenção bricolagística eletrônica" (2005: 65). Nos anos 1990 e 2000, o afloramento da música eletrônica na Europa, elevou o DJ a uma posição cultuada pelo público e pelos pares do mercado cultural, "pois ele entra numa espécie de relação empática com o público, à medida que ele consegue captar o estado de ânimo na pista”, criando intervenções não somente nas músicas, mas no evento em si, o que tornaria as festas comandadas por DJ's um acontecimento sensorial e simbólico único e, portanto, de grande potencial valorativo na cadeia produtiva da cultura popular.

É neste contexto que a música tecnobrega surge em Belém, por um lado, as populações periféricas, já distantes dos territórios rurais tradicionais (de onde emigraram) e alheias aos circuitos culturais elitistas da cidade, vivem num interstício cultural, onde muitas práticas tradicionais são mantidas e re-apropriadas no ambiente (sub)urbano em meio a uma enxurrada de produtos e formatos massivos das grandes mídias; por outro, a corrida tecnológica das cidades aguça a curiosidade e a vontade de experimentar novas formas de criação artística e, assim, estar em dia com a linguagem globalizada dos grandes centros culturais. Em pesquisa de campo nas festas de aparelhagem e estúdios caseiros de Belém, Vianna observou:

Vi, há quinze anos, as aparelhagens ainda tocando discos de vinil. Os DJ's passaram usar CD's, depois MD's e agora só trabalham com MP3's, mixando os sucessos do tecnobrega com o auxílio de mouses e teclados, controlando tudo a partir da tela plana de seus computadores. Eles têm o mesmo fascínio diante da última tecnologia que o público. Nesse sentido são completamente diferentes de DJ's de música eletrônica da classe média brasileira que se organizam em movimentos pró-vinil, tentando manter a tradição analógica da discotecagem. $O$ pessoal das aparelhagens não vacila na hora de jogar fora os equipamentos antigos. Querem ser reconhecidos como os pioneiros, os primeiros a adotar as novidades. O público valoriza essa atitude. As festas mais concorridas são justamente aquelas nas quais as aparelhagens apresentam suas novas "evoluções", cujas principais atrações em termos tecnológicos 
são guardados como segredos de estado até a estréia, para evitar a cópia pelas concorrentes (VIANNA, 2007: 2-3).

Portanto, tecnobrega significa a apropriação livre ou eclética de códigos cult, tradicionais, midiáticos e do excesso misturados com símbolos e equipamentos da mais alta tecnologia, ou seja, no campo do estilo musical, uma mistura de guitarradas caribenhas, batucadas de carimbó com lep tops, softwares de edição digital, sintetizadores, seqüenciadores, samplers; de outro lado, uma mistura de brilhos, cores vivas, tinturas de cabelo, botas, roupas de couro sintético, pirotecnia, coreografias, grandes trupes num espetáculo performático onde é possível identificar códigos ritualísticos caboclos encobertos num enorme aparato tecnológico.

Este aspecto de pastiche pós-moderno, aliado ao movimento de ecletismo cultural das "elites globais extraterritoriais" (BAUMAN, 2003: 52-54) - ecletismo geralmente amparado nas representações estereotipadas e superficializadas de culturas consideradas exóticas sob o ponto de vista das culturas hegemônicas; para Bauman, estas elites globais "habitam uma bolha sociocultural isolada das diferenças mais ásperas entre diferentes culturas nacionais" - são os principais fatores de enquadramento do que é brega ou cult nas sociedades de consumo contemporâneas. A confusão ou hibridação entre estas duas categorias reflete a intenção de rompimento das distinções sociais que formam as fronteiras de classes entre culto e vazio, privilegiados e excluídos (sob a ótica do consumo). Segundo Freire Filho:

As práticas de consumo bregas estão, sem dúvida, relacionadas tanto à autogratificação narcisista, ao hedonismo consumista, à vontade de demolir hierarquias opressivas, à investimentos afetivos de toda sorte, quanto (em especial, no caso dos chamados bregasemergentes) ao desejo de auto-afirmação, ao anseio de prestígio, á tentativa de emular os modelos daqueles situados em escalões mais altos de prestígio da sociedade, granjeando sua simpatia e seu reconhecimento" (FREIRE FILHO, 2003: 11).

É neste contexto que as mídias alternativas começam a emergir como forma de driblar os difíceis sistemas de distribuição e divulgação do mercado formal. Se o tecnobrega apropriou-se livremente de tecnologias e formas de produção e composição musical, as estratégias alternativas de circulação destas produções também foram elaboradas dentro de um contexto específico que envolve canais de comunicação livres do controle financeiro das grandes corporações, formas imateriais de propagação de conteúdos e redes colaborativas informais. Porém, temos 
a clara noção da lógica do consumo, onde, se por um lado um determinado grupo social excluído apropria-se de padrões e tecnologias hegemônicas para fazer-se representar no mundo midiático, por outro, a cultura massiva também toma para si produtos populares para explorar seu potencial de agenciamento ao consumo, muitas vezes reduzindo seus formatos e narrativas a uma simplicidade mais adequada à rapidez do mercado simbólico.

\section{IV - O mercado tecnobrega: números e indicadores de uma mudança no circuito cultural local.}

Segundo Rodrigues (2005: 112-114), a “escuta contemporânea” é marcada principalmente por dois fatores históricos: 1 - a repressão política e religiosa por parte da Igreja Católica à música pulsante e polifônica desde o período gregoriano, no século VI; e 2 - o processo de mercantilização da escuta forjado pela cultura europeizante que se propunha como centro referencial da alta cultura, separando as demais formas de composição e expressão à classificação de baixa cultura. A música européia e seus rituais simbólicos (concertos, teatros, saraus, orquestras particulares, "fetichismo da técnica" e "horror medonho ao erro") sinalizavam uma posição social superior. Em Belém, a figura do Theatro da Paz é emblemática deste período, por representar o que Wisnik denomina "uma moldura visível" da música clássica, ou seja, um espaço sagrado da alta cultura onde qualquer tipo de ruído (sonoro ou cultural) é severamente excluído (2006: 42-43).

Acontece que no circuito tecnobrega, o espaço ritualístico e canônico do teatro é transplantado às festas de aparelhagens, e com isso, os ruídos provenientes da vida urbana, da periferia e das diferenças socioculturais, ganham volume e espaço de ressonância. Segundo pesquisa realizada pela Fundação Getúlio Vargas do Rio de Janeiro, em parceria com o Overmundo e a Fundação Instituto de Pesquisas Econômicas da Usp em 2006, existem cerca de 700 aparelhagens em funcionamento em Belém (fora muitas outras centenas no interior do Estado, onde o mercado do tecnobrega se expande de forma acelerada), que empregam diretamente mais de 4 mil pessoas. É certo que houve uma significativa mudança nas formas de negócio, distribuição, gerenciamento de imagem e lucro no mercado de artistas bregueiros do Pará. Segundo a mesma pesquisa, na cidade de Belém, o mercado do tecnobrega conjuga formalidade com informalidade, envolvendo bandas, festeiros, DJ's de 
aparelhagens, estúdios caseiros e vendedores ambulantes, que movimentam juntos cerca de 8 milhões de Reais por mês (FGV et al.: 8-11), dos quais, pelo menos 1,745 milhão circula no mercado informal dos vendedores de rua, que são ainda os principais responsáveis pela distribuição dos CD’s e DVD's gravados nos estúdios de pequeno porte; esta distribuição tem um papel que vai além da mera acessibilidade física do produto ao consumidor, chegando a funcionar como a principal forma de divulgação das bandas e do próprio estilo; ainda segundo a pesquisa supracitada, 51\% dos artistas incentivam e repassam seus CD'd e DVD's diretamente aos vendedores de rua, e 59\% avaliam positivamente o trabalho dos ambulantes para suas carreiras artísticas.

Os dados de mercado obtidos pela pesquisa demonstram que as estratégias informais têm gerado sustentabilidade financeira aos artistas de uma cidade onde, tradicionalmente, emigrar e projetar-se no mercado nacional são condições diretamente associadas por artistas e públicos. A renda mensal média dos cantores de tecnobrega e das aparelhagens está estimada em mais de 1.600 Reais, o que representa respectivamente 46 e $72 \%$ da renda total de músicos e DJ's que trabalham na cidade. Além disso, o faturamento mensal com a venda de CD's e DVD's de tecnobrega (em camelôs ou durante os shows) ultrapassa dois milhões de Reais e cerca de 180 mil DVD's vendidos por mês (FGV et al.: 11-12).

Estes dados demonstram uma mudança não só no mercado musical, mas no circuito cultural nacional. A histórica centralização da produção cultural massiva no Rio de Janeiro, São Paulo e Bahia, provocou durante décadas a emigração de artistas de cidades periféricas para estes grandes centros. Ainda hoje, o Rio de Janeiro concentra $80 \%$ de toda a produção audiovisual nacional3. Todas as gravadoras multinacionais (as majors) mantêm sedes apenas no Rio de Janeiro e em São Paulo, e mais de 80\% das gravadoras nacionais (inclusive as independentes, popularmente chamadas de indies) estão sediadas na região Sudeste, com 49\% em São Paulo e $28 \%$ no Rio de Janeiro; nota-se que nenhuma foi catalogada em toda a região Norte (GRÁFICO 1). Mesmo assim, a produção musical e a formação de novos circuitos consolidados estão demonstrando resultados significativos fora do antigo eixo

\footnotetext{
3 Anotação em palestra do Professor João Luiz Vieira, do Departamento de Cinema e Vídeo da Universidade Federal Fluminense, em 8 de março de 2007.
} 
cultural centralizado e utilizando-se de sistemas de circulação alternativos, baseados mais na postura colaborativa do que nas antigas competições por estatísticas de venda da indústria fonográfica tradicional. Isso se deve às novas possibilidades de produção-circulação-consumo-interação que vêm sendo experimentadas em territórios antes ocultados pelas grandes mídias, como o Pará.

GRÁFICO 1. Percentagem de Gravadoras Nacionais por Região do Brasil (2005).

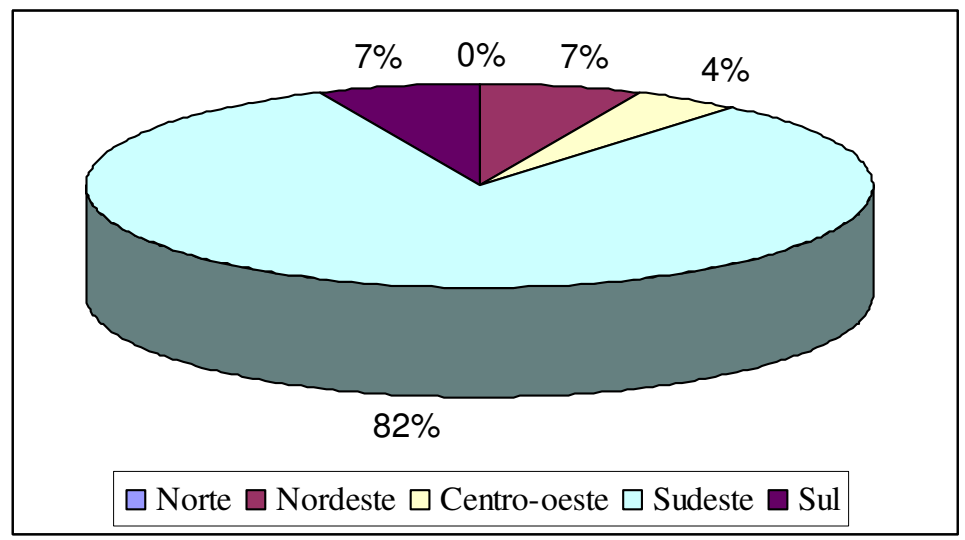

* Fonte: BOULAY (org.), 2005.

\title{
V - Defasagens socioculturais: diversidade cultural e políticas públicas no mercado do tecnobrega:
}

Não pretendemos aqui abordar questões estéticas a respeito do tecnobrega, acreditamos que o gênero tem trilhado uma evolução natural, tanto da emergência constante de novidades tecnológicas, quanto da expansão territorial do tecnobrega, que tem viajado pelo país e, sistematicamente, incorporado novos elementos referenciais, mesmo que geralmente o foco principal dos artistas seja tomar frente na corrida pelo espaço midiático. Guerreiro do Amaral afirma que

\begin{abstract}
Se o tecnobrega é "autenticamente" paraense, é também caracterizado pela "não autenticidade"; ou seja, o som, que é "autêntico", consiste também na recriação (em "versões", para usar um termo nativo) de músicas que estão na crista da onda no circuito mundial das rádios, da produção discográfica, audiovisual e dos espetáculos (GUERREIRO DO AMARAL, 2006a: 4-5).
\end{abstract}

Nosso argumento é que movimentos populares como o tecnobrega do Pará representam uma brecha na passagem de paradigmas de um modelo capitalista 
material e financeiro para um capitalismo cognitivo e imaterial. As alternativas encontradas pelos artistas para circular sua produção e gerar renda a partir da experiência sensorial têm demonstrado resultados concretos no cotidiano local. Além disso, existe um movimento importante de redescrição dos conceitos de cultura popular, alta cultura e folclore local, o que implica diretamente nas políticas públicas locais. A disputa dos artistas e produtores de tecnobrega pelo espaço simbólico nas mídias, no imaginário e no cotidiano popular ajuda a romper, de certa forma, uma forte barreira social criada entorno do gosto culto, ao longo dos últimos quatrocentos anos; o que possibilita repensarmos as políticas de diversidade cultural praticadas atualmente. Somente em 2002 - mesmo anos em que se convencionou determinar a estréia do tecnobrega em Belém (GUERREIRO DO AMARAL, 2006 e VIANNA, 2007) - as emissoras de rádio e TV do Estado do Pará passaram a considerar o tecnobrega como parte da cultura popular paraense, o que representou um marco para o gênero; a partir daí, iniciou-se uma ação coletiva que envolve artistas, produtores, comunicadores, pesquisadores e simpatizantes na busca por legitimação do gênero localmente, uma disputa constante onde trafegam discussões acerca de autenticidade, apropriações, mídias massivas, mercado informal, propriedade intelectual e sustentabilidade financeira.

O grande gargalo das políticas culturais na América Latina como um todo o que se reflete nitidamente numa sociedade como a de Belém, onde a cultura local é dividida entre tradicionalismo folclórico e eruditismo europeizado - é que ainda baseiam-se em conceitos tradicionalistas, puristas e binaristas, onde se tem a idéia de que a contenção de investimentos estrangeiros, o resgate e preservação de tradições "autênticas" e o trato da cultura como "patrimônio cultural" seriam as formas mais adequadas de fazer frente à concorrência industrial globalizada. Na verdade, estas medidas fazem com que uma produção popular menos "autêntica", e nem por isso ilegítima, fique alheia às políticas públicas que privilegiam grupos restritos hora por interesses estatizantes e patrimonialistas, hora por interesses econômicos e políticos.

O fato é que a cultura ainda é considerada como um fator secundário na economia nacional, de modo que as políticas culturais não conseguem abranger um leque mais amplo de produções locais, aquelas que geralmente fogem a um dos dois paradigmas culturais (tradição ou erudição). A legitimação do tecnobrega passa pela 
abertura de espaço à diversidade popular e também pela abertura de conceitos acerca dos padrões de gosto, consumo e formas de circulação cultural. O circuito formado com o mercado informal de distribuição de conteúdos em Belém, assim como o circuito das festas de aparelhagem e performances ao vivo de bandas e cantores, está consolidado e aberto a ampliar-se a um potencial modelo de negócios no campo cultural e comunicacional. Agora, as questões estéticas, narrativas e políticas podem ser repensadas para que se apropriem também deste modelo e façam do mercado cultural alternativo um canal de fala crítica em expansão.

\section{VI - Bibliografia:}

ARAÚJO, Samuel. Brega, Samba e trabalho acústico: variações em torno de uma contribuição teórica à Etnomusicologia. Revista Opus. Belo Horizonte: ANPPOM. n 06, p.1-16, 1999.

BAUMAN, Zygmunt. Comunidade: a busca por segurança no mundo atual. Rio de Janeiro: Jorge Zahar Editor, 2003.

BENTES, Ivana. Redes colaborativas e precariado produtivo. Global. N. 8, março/abril/maio 2007. p. 4-6.

BONJOUR, Ana Maria e CORSINI, Leonora. Viva a cópia! Global. N. 8, março/abril/maio 2007. p. 10-13.

BOULAY, Marinilda Bertolete (org.). Guia do mercado brasileiro da música 2005. São Paulo: Imprensa Oficial e ABMI, 2005.

CANCLINI, Néstor G. Culturas híbridas. São Paulo: Edusp, 2006.

CANCLINI, Néstor G. e MONETA, Carlos Juan. (coords.). Las industrias culturales en la integración latinoamericana. Buenos Aires: Eudeba, 1999.

COCCO, Giuseppe; SILVA, Gerardo; GALVÃO, Alexander Patez. Capitalismo cognitivo. Rio de Janeiro: DP\&A, 2003.

DU GAY, Paul. Productios of culture, cultures of production. London: Uage, 1997.

FUNDAÇÃO GETÚLIO VARGAS; OVERMUNDO; FUNDAÇÃO INSTITUTO DE PESQUISAS ECONÔMICAS. Open business models América Latina: cultura livre, negócios abertos. Rio de Janeiro: Open Business, 2006 (no prelo).

FREIRE FILHO, João. Mídia, consumo cultural e estilo de vida na pós-modernidade. Revista ECO-PÓS. Rio de Janeiro: UFRJ, v. 6, n. 1, p. 72-97, 2003. 
GUERREIRO DO AMARAL, Paulo M. Entre tapas e beijos: o tecnobrega de Belém do Pará. Cafeína Eletroacústica, 2006. Disponível em <http://slog.cafetinaeletroacustica.com/cgi/cgilua.exe/sys/start.htm?infoid= 56\&query=simple\&search\%5Fby\%5Fauthorname=all\&search\%,Fby\%5Ffield =tax\&search $\%_{5}$ Fby ${ }_{5}$ Fheadline $=$ false $\&$ search ${ }_{5}$ Fby $\%{ }_{5}$ Fkeywords $=$ any\&sear ch\%5Fby\%5Fpriority=all\&search $\%{ }_{5}$ Fby\% ${ }_{5}$ Fsection $=$ all\&search $\% 5$ Fby\% ${ }_{5}$ Fsta te $=$ all \&search $\%{ }_{5}$ Ftext $\% 5$ Foptions $=$ all $\&$ sid $=5 \&$ text $=$ paulo + murilo $>$. Acessado em julho de 2007.

GUERREIRO DO AMARAL, Paulo M. Estigma cosmopolitismo local: considerações sobre uma estética legitimadora do tecnobrega em Belém do Pará. In: III Encontro Internacional da ABET, 2006, São Paulo. Universos da Música: cultura, sociabilidade e a política de práticas musicais, 2006a. p. 280285 .

HARDT, M e NEGRI, A. Império. Rio de Janeiro: Record, 2001

HERSCHMANN, Micael. O funk e o hip-hop invadem a cena. Rio de Janeiro: UFRJ, 2005.

LOUREIRO, João de Jesus Paes. Cultura amazônica: uma poética do imaginário. São Paulo: Ed. Escrituras, 2001.

MATTELART, Armand (2006). Diversidad cultural y mundialización. Barcelona: Paidós.

MOULIER-BOUTANG, Yann. Riqueza, propriedade, liberdade e renda no capitalismo cognitivo. Revista Lugar Comum. n. 13-14, p. 25 a 43, 2001.

RODRIGUES, Rodrigo Fonseca e. Música eletrônica: a textura da máquina. Annablume, São Paulo, 2005.

SALLES, Vicente. Épocas do teatro no Grão-Pará ou apresentação do teatro de época. Belém: UFPA, 1994.

SMIERS, Joost. El copyright y el mundo no occidental. Propiedad creativa indebida. Cuadernos de comunicación, tecnología y sociedad. In http://www.campusred.net/TELOS/articuloperspectiva.asp?idarticulo=3\&re $\underline{\mathrm{v}=61} \mathrm{em} 26$ de fevereiro de 2007.

VIANNA, Hermano. Paradas do sucesso periférico. Overmundo, 2007. Disponível em < http://www.overmundo.com.br/banco/paradas-do-sucesso-periferico $>$. Acessado em maio de 2007.

VIANNA, Hermano. A música paralela. Overmundo, 2006. Disponível em <http://www.overmundo.com.br/banco/a-musica-paralela>. Acessado em maio de 2007.

WISNIK, José Miguel. O som e o sentido: uma outra história das músicas. Companhia das Letras, São Paulo, 2006.

ZALLO, Ramón. La vuelta de la política cultural y comunicativa in: Telos. Cuadernos de comunicación, tecnología y sociedad. Madrid: Fundación Telefónica, n. 64, 2005. 